\title{
Anorexia Nervosa Caused by Polymicrobial Tick-Borne Infections: A Case Study
}

\author{
Daniel A Kinderlehrer \\ Private Practice, Denver, CO, \\ 80224, USA
}

Correspondence: Daniel A Kinderlehrer Email kinderlehrer@gmail.com

\begin{abstract}
The etiology of anorexia nervosa (AN) is multifactorial, and infections may play a contributory and possibly a prominent role. A case is presented which is indicative of a causal association between tick-borne infections and AN. This adolescent female was diagnosed with $\mathrm{AN}$ at an eating disorder clinic after excessive food restriction and an irrational fear of weight gain necessitating nasogastric tube feeding. Her history was consistent with systemic infections and she tested serologically positive to Borrelia burgdorferi, Babesia microti, and Mycoplasma pneumoniae; in addition, her clinical presentation was consistent with a Bartonella infection. After treatment with oral and intravenous antimicrobials, she stopped food restriction and no longer had body image concerns. Physicians should be aware of the possibility that tick-borne infections could underly a diagnosis of AN. The role of tick-borne infections in the etiology of AN warrants further study.
\end{abstract}

Keywords: anorexia nervosa, infection, lyme borreliosis, babesia, mycoplasma, bartonella

\section{Introduction}

Anorexia nervosa (AN) is an eating disorder in which patients with an abnormally low body weight have a distorted body image accompanied by an intense fear of gaining weight. People with AN usually severely restrict the quantity of food they eat. They sometimes control calorie intake by vomiting, abusing laxatives, diet aids, diuretics, enemas, or excessive exercise. The fear of weight gain continues regardless of how much weight is lost.

Eating disorders are a major cause of morbidity and mortality. It is estimated that $9 \%$ of the world population suffers from an eating disorder ${ }^{1,2}$ and $9 \%$ of the US population or 28.8 million Americans will have an eating disorder in their lifetime. ${ }^{3}$ It is estimated that $26 \%$ of people with eating disorders attempt suicide and $10 \%$ of people with eating disorders lose their lives as a result of their condition; ${ }^{4,5} \mathrm{AN}$ has the highest mortality rate of any mental disorder. ${ }^{4}$ Eating disorders in children are on the rise-between 1999 and 2006 there was a 119\% increase in hospitalizations related to eating disorders in children less than twelve years of age. ${ }^{6-8}$

AN is considered to be a combination of genetic and environmental factors. Family and twin studies as well as molecular genetic analysis suggest an inheritable vulnerability. ${ }^{9-13}$ Environmental influences include dysfunctional home circumstances and a history of trauma, ${ }^{14,15}$ as well as modern Western culture's emphasis on thinness. ${ }^{16,17}$ However, infections may also play a role in the genesis of AN. ${ }^{18}$ Favaro et al found an association of in utero exposure to viral infections, both varicella and rubella, with the development of $\mathrm{AN}$ in offspring. ${ }^{19}$ Raevuori et al 
described an association of $\mathrm{AN}$ and other eating disorders with patients who had previously been on antibiotic, antiviral, and antifungal medications, ${ }^{20}$ leaving open the question of whether the increase in eating disorders was related to infection, inflammation or pharmaceuticals. Park et al described four patients who experienced the onset of $\mathrm{AN}$ following viral infections, ${ }^{21}$ and Simon described four young children who developed anorexia due to an EpsteinBarr virus infection. ${ }^{22}$ Breithaupt et al studied a nationwide prospective cohort of 525,643 girls in Denmark over 27 years, and correlated the data with hospital admissions for infections and prescribed antimicrobials for infections. They found that hospital treated patients with infections as well as less severe infections treated with antimicrobial agents were associated with an increased risk of $\mathrm{AN}$, bulimia nervosa, and eating disorders that were not otherwise specified. ${ }^{23}$

In 1994, Swedo et al described mental health issues associated with Group A Streptococcus (GAS) infection and coined the condition Pediatric Autoimmune Neuropsychiatric Infections Associated with Streptococcal Infections (PANDAS). ${ }^{24,25}$ Sokol and Gray described the first cases of AN temporally associated with a GAS infection, ${ }^{26}$ and this report was followed by additional case reports of children with PANDAS-like syndromes following GAS infection who developed AN. ${ }^{27-29}$ When it became clear that in addition to GAS, multiple microbes could trigger a PANDAS-like syndrome, the syndrome's nomenclature was updated to Pediatric Acute-onset Neuropsychiatric Syndrome (PANS), of which PANDAS is a subset. Criteria were developed at the First PANS Consensus Conference in 2013, and the primary criteria include obsessive-compulsive disorder (OCD) or severely restricted food intake with no known neurological or medical condition that would account for these symptoms. ${ }^{30}$

The identification of PANS as including anorexic pathology has illuminated the role of infection induced autoimmunity in the genesis of some patients with eating disorders. Zerwas et al performed a nationwide, population-based study of all children and adolescents born in Denmark between 1989 and 2006, and managed until 2012. The study population included 930,977 individuals. They found a significantly higher risk of eating disorders in both children and adolescents with autoimmune illness $-36 \%$ higher risk for $\mathrm{AN}, 73 \%$ for bulimia nervosa, and $72 \%$ for unspecified eating disorders. ${ }^{31}$ In children and adolescents with PANS, it appears that "an infection can cause a cascade of immunological, psychological, and physical symptoms that can lead to an abrupt restriction and/or avoidance of food." 32

Molecular mimicry has been proposed in the autoimmune etiology of PANS-like syndromes - antibodies to microbes cross the blood-brain barrier and provoke psychiatric and neurologic symptoms. ${ }^{33}$ Early attention implicated autoantibodies against $\alpha$-melanocyte stimulating hormone (alpha-MSH), which is involved in the regulation of appetite, body weight, behavior, and mood. ${ }^{34}$ Elevated levels of autoantibodies to neuronal proteins have been identified in PANS/PANDAS patients including against dopamine receptors, ${ }^{35-37}$ lysoganglioside, ${ }^{38}$ and tubulin. ${ }^{39}$ These autoantibodies have been associated with activation of calcium calmodulin-dependent protein kinase II (CaMKII), a multifunctional enzyme highly concentrated in the brain that mediates many different learning, memory, and developmental cell pathways, as well as altering dopamine transmission that can lead to neuropsychiatric symptoms. $^{38,40,41}$

While anorexia is a common symptom in patients with both acute and chronic infection, ${ }^{42}$ a literature search could find only one case report of AN associated with a tick-borne infection, Lyme borreliosis. ${ }^{43}$ The patient described in the present case history was diagnosed with multiple tick-borne infections: Lyme borreliosis, babesiosis, mycoplasmosis, and bartonellosis. Neuroborreliosis has been linked to multiple neuropsychiatric syndromes including depression, anxiety disorders, bipolar disorder, anhedonia, addictions, suicide, depersonalization and dissociative episodes. ${ }^{44-50}$ Babesiosis has been associated with neuropsychiatric disorders as well, particularly anxiety and depression, although the reports of this association have been in the context of Babesia co-infections in patients who also have Lyme disease. ${ }^{44-47}$

Mycoplasma pneumoniae ( $M$. pneumoniae) is best known as a respiratory pathogen, but it can also be tickborne $^{51}$ and result in significant systemic inflammation. ${ }^{52,53}$ Mycoplasma spp. can invade the central nervous system and can trigger autoimmune inflammation in organs throughout the body, including vasculitis, arthritis, meningitis and encephalitis. ${ }^{54-59}$ Infection with $M$. pneumoniae can cause neuropsychiatric symptoms including acute psychosis, ${ }^{60,61}$ OCD ${ }^{62}$ and mania. ${ }^{63}$ In addition, M. pneumoniae has been identified as a PANS trigger. ${ }^{32,64,65}$

Bartonella spp. are transmitted to humans via cat scratches, animal bites, and sand fleas. ${ }^{66}$ In addition, Bartonella can be transmitted via tick vectors, ${ }^{66-68}$ and may be a common co-infection with Lyme borreliosis. ${ }^{69-71}$ 
Bartonella spp. are responsible for a wide spectrum of clinical syndromes in humans, including both neurological and psychiatric illness. ${ }^{72-75}$ The latter category includes depression, anxiety disorder, panic disorder, OCD, phobias, alcohol and drug abuse, psychosis, and personality disorders. ${ }^{75-77}$ In addition, Bartonella is associated with a wide spectrum of autoimmune conditions. ${ }^{7-92}$ Breitschwerdt et al have described a child with PANS that was triggered by Bartonella henselae (B. henselae) infection. ${ }^{77}$

\section{Methods}

A case is presented of an immunocompetent adolescent female diagnosed with AN who was serologically positive for Borrelia burgdorferi (B. burgdorferi), Babesia microti (B. microti), and M. pneumoniae, and clinically diagnosed with Bartonella infection, who responded to antimicrobial treatment to these infections and has remained in sustained remission from her eating disorder.

Informed consent was obtained from the parents of this patient to publish this history as well as the photograph in Figure 1. Institutional review was not required to publish the case details.

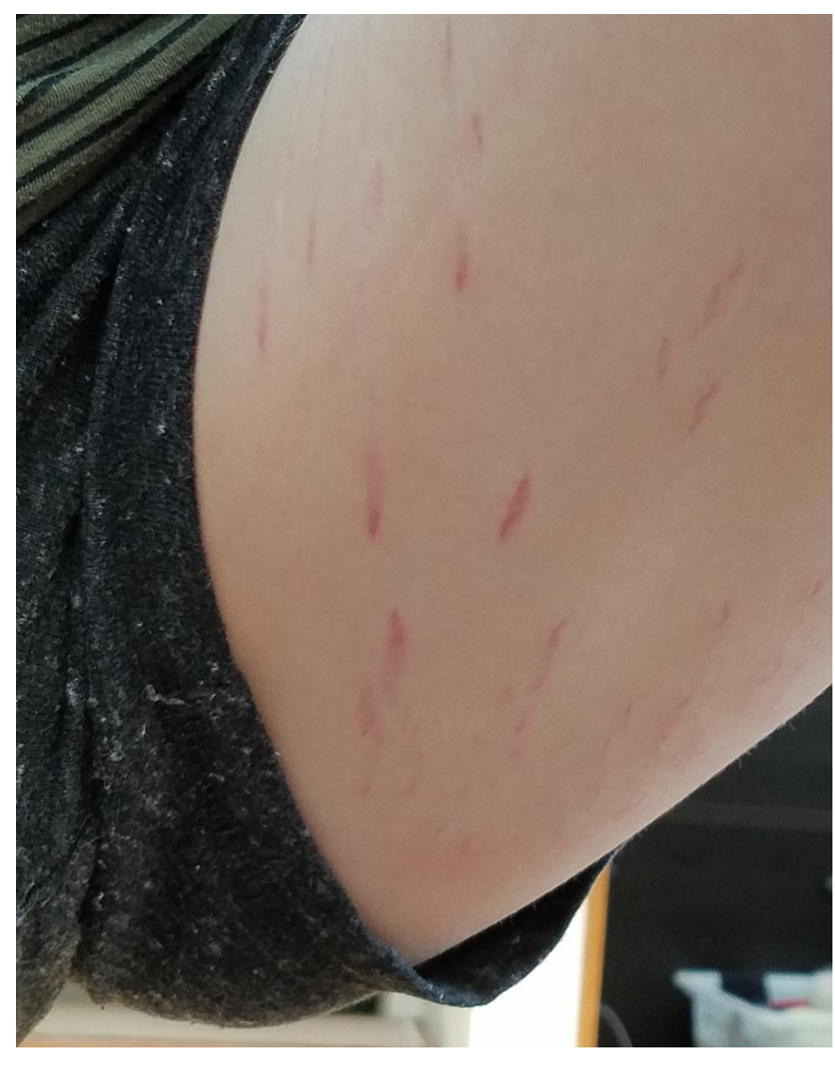

Figure I Striae on medial aspect of left thigh.

\section{Case Presentation}

This female patient initially presented at seventeen years of age having been diagnosed with anorexia nervosa. She lived in upstate New York from two until sixteen years of age. As a young child in upstate New York, she had several tick attachments but no observed rash and no known infections. She had a healthy infancy and normal developmental milestones but at two years of age began screaming and pulling out her hair for no accountable reason (trichotillomania). By four years of age, she experienced social anxiety and gradually developed generalized anxiety and irritability. At twelve years of age, she began complaining of fatigue and frequent sore throats with anterior cervical adenopathy. At fourteen years of age, this patient had yet another tick attachment which led to a two-centimeter erythematous tender rash but no other immediate sequelae, and she was not treated. However, over the next year her fatigue worsened, and she experienced impaired cognition, postural lightheadedness, sleep disturbances, and worsening anxiety and irritability as well as depression.

At fifteen years of age, the patient began restricting her food intake and purging after meals with forced vomiting leading to an admission to an eating disorder unit at age sixteen; she was diagnosed with $\mathrm{AN}$ at that time. Separate trials on sertraline and fluoxetine led to suicidal ideation, but aripiprazole afforded some benefit. She was discharged after two weeks and entered an intensive outpatient program for two months, but was readmitted to an inpatient program due to refusal to eat and suicidal thought with intent. Nasogastric tube feeding was commenced at that time. She was again discharged but readmitted after two weeks because of suicidal thought with intent. She continued to receive tube feedings intermittently when she refused food intake, and was readmitted three months later with suicidal intent and was placed on desvenlafaxine. She was readmitted after another month refusing to eat. She was fed through a dobhoff tube and discharged but after another month needed to be readmitted after pulling out her tube and refusing to eat. This cycle repeated itself one more time, and at the time I initially evaluated her, she was attending an outpatient eating disorder program. Despite intensive interventions with inpatient and outpatient psychotherapy, behavioral interventions, and psychotropic medication, she continued to refuse oral food intake.

At the time of her initial visit the patient was taking desvenlafaxine and aripiprazole as well as lorazepam and 
melatonin at bedtime. She had the nasogastric tube in place and stated that she was otherwise refusing to eat. She maintained that she still had an overweight issue and had to stay on a restricted diet. She continued to describe anxiety, depression, and irritability as well as fatigue, impaired cognition with poor concentration, errors in speech, non-restorative sleep with early morning awakening, postural lightheadedness, and frequent sore throats with enlarged cervical nodes. In addition, she complained of numbness and paresthesias in her hands and toes, neck and hip pain, and muscle twitching. Physical examination revealed she was 66 inches in height and weight was $58 \mathrm{~kg}$; sitting blood pressure was $130 / 80 \mathrm{mmHg}$ with a pulse of 80 beats per minute (bpm) and blood pressure was 118/60 mmHg with a pulse of $100 \mathrm{bpm}$ standing. The remainder of the examination was unremarkable with the exception of her skin. There were prominent erythematous striae on her breasts, hips, and thighs. The patient described these striations as stretch marks and indicative of her overweight issue. A picture of these striae on her left medial thigh is in Figure 1.

Laboratory evaluation revealed normal routine blood counts and chemistries as well as quantitative immunoglobulins. She had negative antinuclear antibodies (ANA) and GAD-65 autoantibody. Testing for tick-borne infections revealed the following:

- Lyme Western blot IgM positive at 18, 39, 41, 66 and 83-93 kDa bands.

- Lyme Western blot IgG positive at 28 and $41 \mathrm{kDa}$ bands.

- B. microti serum immunofluorescent antibody (IFA) $\operatorname{IgM}=40$ (reference range $[\mathrm{RR}]:<20$ ).

- B. microti IFA IgG <40 (RR: <40).

- Human monocytic ehrlichia (HME) IgM <20 (RR: $<20)$.

- HME IgG <40 (RR: <40).

- Human granulocytic anaplasma (HGA) IgM <20 (RR: <20).

- HGA IgG <40 (RR: <40).

- Bartonella henselae (B. henselae) IgM<20 (RR: $<20$ ).

- B. henselae $\mathrm{IgG}<40$ (RR: <40).

- M. pneumoniae $\operatorname{IgM}=3581(\mathrm{RR}<20)$.

- M. pneumoniae $\operatorname{IgG}=2010(\mathrm{RR}<40)$.

The patient was diagnosed clinically and serologically with Lyme borreliosis, babesiosis, and mycoplasmosis, and initially treated with oral azithromycin $250 \mathrm{mg}$ twice daily to treat infections with $B$. burgdorferi and M. pneumoniae, and artemisinin $100 \mathrm{mg}$ every other day to treat Babesia. In addition, the patient was clinically diagnosed with bartonellosis, and began sulfamethoxazole/trimethoprim (SXT) at $800 \mathrm{mg} / 160 \mathrm{mg}$ twice daily. The introduction of SXT triggered an increase in her hip pain, and she was more adamant in her refusal to eat, leading to discontinuation of the SXT. The patient was then started on intravenous ceftriaxone 2 gm daily administered through a peripherally inserted central catheter (PICC), after which she began improving. Artemisinin dose was progressed to $200 \mathrm{mg}$ twice daily four days out of seven, and SXT was restarted at $400 \mathrm{mg} / 80 \mathrm{mg}$, both of which were well tolerated. Postural lightheadedness continued to be problematic and repeat vital signs revealed $\mathrm{BP}=96 / 60 \mathrm{mmHg}$ with pulse $80 \mathrm{bpm}$ sitting and $\mathrm{BP}=86 / 66$ $\mathrm{mmHg}$ with pulse $132 \mathrm{bpm}$ standing accompanied by symptoms of near-syncope. The patient was diagnosed with postural orthostatic tachycardia syndrome (POTS) and started on midodrine $5 \mathrm{mg}$ twice daily with resolution of her lightheaded symptoms.

At this point, she was consuming a normal caloric intake and no longer required the nasogastric tube. When SXT was increased to $800 \mathrm{mg} / 160 \mathrm{mg}$ twice daily the patient again had thoughts of not eating; these thoughts stopped when she decreased the dose. This response was interpreted as a Jarisch-Herxheimer reaction (JHR), which is a flare in symptoms coincident with the introduction of antimicrobial agents. After one week the decision was made to increase her dose of SXT gradually. She increased the dose of SXT to $800 \mathrm{mg} / 160 \mathrm{mg}$ in the morning and $400 \mathrm{mg} / 80 \mathrm{mg}$ in the evening, and one week later increased to $800 \mathrm{mg} / 160 \mathrm{mg}$ twice daily and it was tolerated well without a JHR.

Intravenous ceftriaxone was discontinued after three months and the patient began cefdinir $300 \mathrm{mg}$ twice daily. The patient was maintained on cefdinir, and continued the azithromycin and SXT for a total of one year, during which her eating disorder stayed in remission and her other symptoms gradually resolved. She continued to take desvenlafaxine but she no longer complained of depression, and anxiety was minimal. By that time her energy, sleep, and cognition were good, and she no longer complained of neck or hip pains, sore throats or swollen cervical nodes. The striae were no longer erythematous. Two years since discontinuing antibiotics, these symptoms have remained in remission. 


\section{Discussion}

This patient presented with multiple symptoms, a clinical diagnosis of $\mathrm{AN}$, and positive serologies to B. burgdorferi, B. microti, and M. pneumoniae. (The patient's Lyme IgM Western blot was CDC positive for Lyme disease; it is noteworthy that persistent IgM positivity to B. burgdorferi is consistent with chronic infection. ${ }^{93,94}$ ) In addition, she was clinically diagnosed with bartonellosis.

The clinical evidence for the diagnosis of bartonellosis in this patient is supported by the presence of dermatological striae that were not in the normal skin plains seen with striae distensae, ie, stretch marks. Nor did she ever experience abnormal weight gain, rapid or otherwise, that would account for striae distensae; nor was there evidence of hypercortisolism. Rather, these striae have been described in patients with Bartonella infections, and are a result of neovascularization that is stimulated by this microbe. ${ }^{95}$ Breitschwerdt et al described 29 patients who had serological and/or PCR evidence of Bartonella infection, 24 of whom described the onset of cutaneous lesions since the onset of neuropsychiatric symptoms. ${ }^{96}$ The majority of those lesions were similar to the striae that this patient manifested on presentation. Bartonella immunoreactivity has been detected in skin-tissue biopsies in these lesions. ${ }^{97}$ Further evidence of Bartonella infection in this patient is the provocation of Jarisch-Herxheimer reactions when she was started on SXT, or the dose of SXT was increased; when SXT was introduced, she experienced an increase in hip pain and was more adamant in her refusal to eat, and SXT has anti-Bartonella activity. ${ }^{98}$

Bartonella is a common co-infection of Lyme borreliosis. In a survey of Ixodes ticks in northern New Jersey, Adelson et al found that $35 \%$ harbored B. burgdorferi while $34 \%$ were colonized with Bartonella spp. ${ }^{69}$ Additional studies of Ixodes ticks have also found a high incidence of Bartonella spp., ${ }^{70,71}$ and case studies have documented Bartonella seropositivity and the presence of Bartonella DNA in the serum of patients with $B$. burgdorferi infection of the nervous system. ${ }^{72,73}$ This patient was seronegative for $B$. henselae, but false negative serological results are frequent. ${ }^{99}$ Bartonella spp. other than $B$. henselae have caused infection in humans, ${ }^{100}$ which may account for false negative serologies when testing for only $B$. henselae.

As noted above, Bartonella infection is associated with a wide range of neuropsychiatric symptoms and autoimmune conditions, including PANS ${ }^{75-92}$ although a literature review did not disclose a case of anorexia nervosa. This patient's JHR in response to SXT, which resulted in increased resistance to oral food intake, suggests the possible role of Bartonella infection in the pathogenesis of her eating disorder.

Regarding Mycoplasma, Toufexis et al described four children with PANS and eating restrictions who had positive IgG titers to M. pneumoniae, but only one of whom also had an elevation in her IgM antibodies. ${ }^{32}$ Their report does not cite the actual titers of IgG and IgM antibodies. It is not clear whether M. pneumoniae was playing a role in the subjects with PANS since there is a high background of IgG prevalence in control populations, ${ }^{101,102}$ and $\operatorname{IgM}$ false positivity occurs in the setting of other infections due to cross-reactivity. ${ }^{103}$ Similarly, Piras et al described a case of PANS with "a positive test for Mycoplasma pneumoniae", in which the subject responded to clarithromycin; neither the IgM nor the IgG titers were reported. ${ }^{64}$ On the other hand, Frankovich et al, in their series of five cases with PANS, describe one subject who had significant elevations in both $\operatorname{IgM}$ and $\operatorname{IgG}$ titers to M. pneumoniae. $^{65}$ The patient in this current report had high levels of both IgM and IgG antibodies to M. pneumoniae, thus confirming active infection with this microbe.

Babesiosis can result in anorexia, ${ }^{104}$ but there are no case reports in the medical literature connecting Babesia infection with PANS, AN or other eating disorders. Babesia infection is a well-documented cause of autoimmune hemolytic anemia, particularly in its acute stage, but it has not been linked to other autoimmune conditions. ${ }^{104}$

Neuroinflammation occurs in both acute and persistent infection with Lyme borreliosis. ${ }^{105,106}$ Persistent infection with $B$. burgdorferi can induce chronic autoimmune disease, ${ }^{107}$ and anti-neuronal antibodies are present in many patients with persistent symptoms following treatment for Lyme borreliosis. ${ }^{108}$ As yet there are no reports of B. burgdorferi as a trigger for PANS. Neuropsychiatric symptoms associated with Lyme borreliosis are similar to those with PANS, including anxiety, depression, OCD and tics. $^{44-50,109}$

Review articles cite the occurrence of eating disorders and, specifically, AN in patients with Lyme borreliosis, ${ }^{44-47}$ but a review of the medical literature revealed only one case history of AN associated with Lyme disease. Pachner et al described a twelve-year-old boy who initially presented with intermittent swelling of his right knee. He was serologically positive for Lyme disease and was treated with doxycycline $100 \mathrm{mg}$ twice daily for thirty days with resolution of his knee swelling. 
Two months later he became depressed, withdrawn, restricted his food intake, exercised compulsively, and lost $14 \mathrm{~kg}$. Immunoblotting of his serum revealed antibodies to outer surface protein (Osp) A and Osp B. He was treated with intravenous penicillin 20 million $\mathrm{U} /$ day for 14 days and within weeks he increased his food intake, gained weight, and was no longer depressed. ${ }^{43}$

Similarly, this patient responded well to an antimicrobial regimen directed at her polymicrobial tick-borne infections, and two years since the cessation of her antibiotics she has remained asymptomatic and free of her prior symptoms of an eating disorder. This patient may indeed have suffered from a PANS-like syndrome starting at the age of two when she exhibited trichotillomania followed by the development of a generalized anxiety disorder. While she did not exhibit OCD, trichotillomania has similarities to OCD, although there are differences between the two disorders as well. ${ }^{110}$ The eating disorder appeared to occur after another tick attachment when she was 14-years-old that exposed her to a reinfection or to additional tick-borne pathogens. All four of the tick-borne pathogens with which she was infected are associated with autoimmunity, and three of them are linked to neuroinflammation-B. burgdorferi, M. pneumoniae, and B. henselae. Any one or all these infections could have contributed to this patient's eating disorder.

\section{Conclusion}

There is increasing support for the role of infections in the genesis of AN in some patients. The data suggest that autoimmunity is playing a prominent role in the pathogenesis of microbial-induced $\mathrm{AN}$, and that role has been elucidated in children and adolescents with PANS. This is the first documented case of Lyme borreliosis complicated by three coinfections triggering AN. This adds to the existing literature that infections can play a more prominent role in AN. The corollary is that physicians should become aware of this association in the evaluation of patients with $\mathrm{AN}$, as it may provide a treatment option for this serious and sometimes fatal condition. The possibility that tick-borne infections could underlie the diagnosis of AN warrants further study.

\section{Acknowledgments}

The author wishes to thank Drs. Rosalie Greenberg and Robert Bransfield for their assistance in the preparation of this manuscript.

\section{Disclosure}

The author reported no conflicts of interest for this work.

\section{References}

1. Galmiche M, Dechelotte P, Lambert G, Tavolacci MP. Prevalence of eating disorders over the 2000-2018 period: a systematic literature review. Am J Clin Nutr. 2019;109(5):1402-1413. doi:10. 1093/ajen/nqy342

2. Hoek HW. Review of the worldwide epidemiology of eating disorders. Curr Opin Psychiatry. 2016;29(6):336-339. doi:10. 1097/YCO.0000000000000282

3. Deloitte Access Economics. The Social and Economic Cost of Eating Disorders in the United States of America: A Report for the Strategic Training Initiative for the Prevention of Eating Disorders and the Academy for Eating Disorders. June 2020. Available from: https://anad.org/education-and-awareness/abouteating-disorders/eating-disorders-statistics/. Accessed May 4, 2021.

4. Arcelus J, Mitchell AJ, Wales J, Nielsen S. Mortality rates in patients with anorexia nervosa and other eating disorders: a meta-analysis of 36 studies. Arch Gen Psychiatry. 2011;68 (7):724-731. doi:10.1001/archgenpsychiatry.2011.74

5. Chesney E, Goodwin GM, Fazel S. Risks of all-cause and suicide mortality in mental disorders: a meta-review. World Psychiatry. 2014;13(2):153-160. doi:10.1002/wps.20128

6. Udo T, Bitley S, Grilo CM. Suicide attempts in US adults with lifetime DSM-5 eating disorders. BMC Med. 2019;17:120. doi:10. 1186/s12916-019-1352-3

7. Halmi KA. Anorexia nervosa: an increasing problem in children and adolescents. Dialogues Clin Neurosci. 2009;11(1):100-103.

8. Hudson JI, Hiripi E, Pope HG Jr, Kessler RC. The prevalence and correlates of eating disorders in the National comorbidity survey replication. Biol Psychiatry. 2007;61(3):348-358. doi:10.1016/j. biopsych.2006.03.040

9. Pinheiro AP, Root T, Bulik CM. The genetics of anorexia nervosa: current findings and future perspectives. Int $J$ Child Adolesc Health. 2002;2(2):153-164.

10. Watson HJ, Yilmaz Z, Thornton LM, et al. Genome-wide association study identifies eight risk loci and implicates metabo-psychiatric origins for anorexia nervosa. Nat Genet. 2019;51:1207-1214. doi:10.1038/s41588-019-0439-2

11. Yilmaz Z, Hardaway JA, Bulik CM. Genetics and epigenetics of eating disorders. Adv Genomics Genet. 2015;5:131-150. doi:10. 2147/AGG.S55776

12. Bulik CM, Slof-op't landt MC, van Furth EF, Sullivan PF. The genetics of anorexia nervosa. Annu Rev Nutr. 2007;27:263-275. doi:10.1146/annurev.nutr.27.061406.093713

13. Berrettini W. The genetics of eating disorders. Psychiatry. 2004;1 (3): $18-25$

14. Ferrell EL, Russin SE, Flint DD. Prevalence estimates of comorbid eating disorders and posttraumatic stress disorder: a quantitative synthesis. J Aggress Maltreat Trauma. 2020; 20:1-19. doi:10.1080/10926771.2020.1832168

15. Tagay S, Schlottbohm E, Reyes-Rodriguez ML, Repic N, Senf W. Eating disorders, trauma, PTSD, and psychosocial resources. Eat Disord. 2014;22(1):33-49. doi:10.1080/10640266.2014.857517

16. Becker AE, Fay KE, Agnew-Blais J, Khan AN, Striegel-Moore RH, Gilman SE. Social network media exposure and adolescent eating pathology in Fiji. Br J Psychiatry. 2011;198(1):43-50. doi:10.1192/bjp.bp.110.078675

17. Kiriike N, Nagata T, Tanaka M, Nishiwaki S, Takeuchi N, Kawakita Y. Prevalence of binge-eating and bulimia among adolescent women in Japan. Psychiatry Res. 1988;26:163-169. doi:10.1016/0165-1781(88)90071-6 
18. Brown RF, Bartrop R, Beumont P, Birmingham CL. Bacterial infections in anorexia nervosa: delayed recognition increases complications. Int J Eat Disord. 2005;37(3):261-265. doi:10. 1002/eat.20135

19. Favaro A, Tenconi E, Ceschin L, Zanetti T, Bosello R, Santonastaso P. In utero exposure to virus infections and the risk of developing anorexia nervosa. Psychol Med. 2011;41 (10):2193-2199. doi:10.1017/S0033291710002655

20. Raevuori A, Lukkariniemi L, Suokas JT, Gissler M, Suvisaari JM, Haukka J. Increased use of antimicrobial medication in bulimia nervosa and binge-eating disorder prior to the eating disorder treatment. Int J Eat Disord. 2016;49(6):542-552. doi:10.1002/eat.22497

21. Park RJ, Lawrie SM, Freeman CP. Post-viral onset of anorexia nervosa. Br J Psychiatry. 1995;166(3):386-389. doi:10.1192/bjp. 166.3.386

22. Simon MW. Anorexia and failure to grow associated with Epstein-Barr virus infection. J Ky Med Assoc. 1998;96(1):13-15.

23. Breithaupt L, Köhler-Forsberg O, Larsen JT, et al. Association of exposure to infections in childhood with risk of eating disorders in adolescent girls. JAMA Psychiatry. 2019;76(8):800-809. doi:10.1001/jamapsychiatry.2019.0297

24. Swedo SE, Leonard HL, Kiessling LS. Speculations on antineuronal antibody-mediated neuropsychiatric disorders of childhood. Pediatrics. 1994;93(2):323-326.

25. Swedo SE, Leonard HL, Garvey M, et al. Pediatric autoimmune neuropsychiatric disorders associated with streptococcal infections: clinical description of the first 50 cases. Am J Psychiatry. 1998;155(2):264-271. doi:10.1176/ajp.155.2.264

26. Sokol MS, Gray NS. Case study: an infection-triggered, autoimmune subtype of anorexia nervosa. J Am Acad Child Adolesc Psychiatry. 1997;36(8):1128-1133. doi:10.1097/00004583-19970 8000-00021

27. Henry MC, Perlmutter SJ, Swedo SEAnorexia, OCD, and streptococcus. J Am Acad Child Adolesc Psychiatry. 1999;38:228-229. doi:10.1097/00004583-199903000-00002

28. Sokol MS. Infection-triggered anorexia nervosa in children: clinical description of four cases. J Child Adolesc Psychopharmacol. 2000;10(2):133-145. doi:10.1089/cap.2000.10.133

29. Calkin CV, Carandang CG. Certain eating disorders may be a neuropsychiatric manifestation of PANDAS: case report. J Can Acad Child Adolesc Psychiatry. 2007;16(3):132-135.

30. Chang K, Frankovich J, Cooperstock M, et al. Clinical evaluation of youth with Pediatric Acute-Onset Neuropsychiatric Syndrome (PANS): recommendations from the 2013 PANS consensus conference. $J$ Child Adolesc Psychopharmacol. 2015;25 (1):3-13. doi:10.1089/cap.2014.0084

31. Zerwas S, Larsen JT, Petersen L, et al. Eating disorders, autoimmune, and autoinflammatory disease. Pediatrics. 2017;140(6): e20162089. doi:10.1542/peds.2016-2089

32. Toufexis MD, Hommer R, Gerardi DM, et al. Disordered eating and food restrictions in children with PANDAS/PANS. $J$ Child Adolesc Psychopharmacol. 2015;25(1):48-56. doi:10.1089/cap. 2014.0063

33. Fetissov SO, Harro J, Jaanisk M, et al. Autoantibodies against neuropeptides are associated with psychological traits in eating disorders. Proc Natl Acad Sci USA. 2005;102(41):14865-14870. doi:10.1073/pnas.0507204102

34. Coquerel Q, Sinno MH, Boukhettala N, et al. Intestinal inflammation influences -MSH reactive autoantibodies: relevance to food intake and body weight. Psychoneuroendocrinology. 2012;37:94-106. doi:10.1016/j.psyneuen.2011.05.008

35. Cunningham MW, Cox CJ. Autoimmunity against dopamine receptors in neuropsychiatric and movement disorders: a review of Sydenham chorea and beyond. Acta Physiol. 2016;216 (1):90-100. doi:10.1111/apha.12614
36. Cox CJ, Sharma M, Leckman JF, et al. Brain human monoclonal autoantibody from Sydenham chorea targets dopaminergic neurons in transgenic mice and signals dopamine D2 receptor: implications in human disease. J Immunol. 2013;191(11):5524-5541. doi:10.4049/jimmunol.1102592

37. Brimberg L, Benhar I, Mascaro-Blanco A, et al. Behavioral, pharmacological, and immunological abnormalities after streptococcal exposure: a novel rat model of Sydenham chorea and related neuropsychiatric disorders. Neuropsychopharmacology. 2012;37(9):2076-2087. doi:10.1038/npp.2012.56

38. Kirvan CA, Swedo SE, Heuser JS, Cunningham MW. Mimicry and autoantibody-mediated neuronal cell signaling in Sydenham chorea. Nat Med. 2003;9(7):914-920. doi:10.1038/nm892

39. Kirvan CA, Cox CJ, Swedo SE, Cunningham MW. Tubulin is a neuronal target of autoantibodies in sydenham's chorea. J Immunol. 2007;178(11):7412-7421. doi:10.4049/jimmunol.17 8.11.7412

40. Cox CJ, Zuccolo AJ, Edwards EV, et al. Antineuronal antibodies in a Heterogeneous Group of youth and young adults with tics and obsessive-compulsive disorder. $J$ Child Adolesc Psychopharmacol. 2015;25(1):76-85. doi:10.1089/cap.2014.0048

41. Robison AJ. Emerging role of CaMKII in neuropsychiatric disease. Trends Neurosci. 2014;37(11):653-662. doi:10.1016/j. tins.2014.07.001

42. Kanra GY, Ozen H, Kara A. Infection and anorexia. Turk J Pediatr. 2006;48(4):279-287.

43. Pachner AR, Duray P, Steere AC. Central nervous system manifestations of lyme disease. Arch Neurol. 1989;46(7):790-795. doi:10.1001/archneur.1989.00520430086023

44. Bransfield R. Neuropsychiatric lyme borreliosis: an overview with a focus on a specialty psychiatrist's clinical practice. Healthcare. 2018;6(104):1-23.

45. Bransfield RC. Lyme disease, comorbid tick-borne diseases, and neuropsychiatric disorders. Psychiatr Times. 2007;24(14):59-61.

46. Fallon BA, Nields JA, Burrascano JJ, Liegner K, Delbene D, Liebowitz MR. The neuropsychiatric manifestations of lyme borreliosis. Psychiatr Q. 1992;63(1):95-117. doi:10.1007/BF01 064684

47. Fallon BA, Nields JA. Lyme disease: a neuropsychiatric illness. Am J Psychiatry. 1994;151(11):1571-1583.

48. Fallon BA, Kochevar JM, Gaito A, Nields JA. The underdiagnosis of neuropsychiatric lyme disease in children and adults. Psychiatr Clin N Am. 1998;21(3):693-703. doi:10.1016/S0193953X(05)70032-0

49. Bransfield RC. Aggressiveness, violence, homicidality, homicide, and lyme disease. Neuropsychiatric Dis Treat. 2018;14:693-713. doi:10.2147/NDT.S155143

50. Greenberg R. Aggressiveness, violence, homicidality, homicide, and lyme disease. Neuropsychiatr Dis Treat. 2018;14:1253-1254. doi:10.2147/NDT.S168751

51. Hornok S, Mell ML, Farkas R. Molecular investigation of hard ticks (Acari: ixodidae) and fleas (Siphonaptera: pulicidae) as potential vectors of rickettsial and mycoplasmal agents. Vet Microbiol. 2009;140(1-2):98-104. doi:10.1016/j.vetmic.2009.07. 013

52. Berghoff W. Chronic lyme disease and co-infections. Open Neurol J. 2012;6:158-178. doi:10.2174/1874205X01206010158

53. Yang J. Regulation of proinflammatory cytokines in human lung epithelial cells infected with mycoplasma pneumonia. Infect Immun. 2002;70(7):3649-3655. doi:10.1128/IAI.70.7.3649-3655. 2002

54. Guleria R, Nisar N, Chawla TC, Biswas NR. Mycoplasma pneumoniae and central nervous system complications: a review. J Lab Clin Med. 2005;146(2):55-63. doi:10.1016/j.lab.2005.04.006

55. Waites KB, Talkington TF. Mycoplasma pneumoniae and its role as a human pathogen. Clin Microbiol Rev. 2004;17(4):697-728. 
56. Sherbet G. Bacterial infections and the pathogenesis of autoimmune conditions. BJMP. 2009;2(1):6-13.

57. Patino B, Maestu RP, de Letona JML. Mechanisms of disease in mycoplasma pneumoniae infection. [article in Spanish]. Rev Clin Esp. 2004;204(7):365-368. doi:10.1157/13063528

58. Greco F, Sorge A, Salvo V, Sorge G. Cutaneous vasculitis associated with mycoplasma pneumoniae infection: case report and literature review. Clin Pediatr. 2007;46(5):451-453. doi:10.1177/ 0009922806298638

59. Baseman JB, Tully JG. Mycoplasmas: sophisticated, reemerging, and burdened by their notoriety. Emerg Infect Dis. 1997;3 (1):21-32. doi:10.3201/eid0301.970103

60. Bannerjee B, Peterson K. Psychosis following mycoplasma pneumonia. Mil Med. 2009;174(9):1001-1004. doi:10.7205/ MILMED-D-00-8209

61. Moor S, Skrine H. Psychosis in mycoplasma infection. Postgrad Med J. 1989;65(760):96-97. doi:10.1136/pgmj.65.760.96

62. Ercan TE, Ercan G, Severge B, Arpaozu M, Karasu G. Mycoplasma pneumoniae infection and obsessive-compulsive disease: a case report. J Child Neurol. 2008;23(3):338-340. doi:10.1177/0883073807308714

63. Becker MA, Cannon J, Certa K. A case of mycoplasma pneumoniae encephalopathy presenting as mania. Psychosomatics. 2021;62(1):150-154

64. Piras C, Pintas R, Pruna D, Dessi A, Atzoril L, Fanos V. Pediatric acute-onset neuropsychiatric syndrome and mycoplasma pneumoniae infection: a case report analysis with a metabolomics approach. Curr Pediatr Rev. 2020;16(3):183-193. doi:10.2174/ 1573396315666191022102925

65. Frankovich J, Thienemann M, Rana S, Chang K. Five youth with pediatric acute-onset neuropsychiatric syndrome of differing etiologies. J Child Adolesc Psychopharmacol. 2015;25(1):3 1-37. doi:10.1089/cap.2014.0056

66. Billeter S, Levy M, Chomel B, Breitschwerdt E. Vector transmission of bartonella species with emphasis on the potential for tick transmission. Med Vet Entomol. 2008;22:1-15. doi:10.1111/ j.1365-2915.2008.00713.x

67. Reis C, Cote M, Le Rhun D, et al. Vector competence of the tick Ixodes ricinus for transmission of Bartonella birtlesii. PLoS Negl Trop Dis. 2011;5:e1186. doi:10.1371/journal.pntd.0001186

68. Cotté V, Bonnet S, Le Rhun D, et al. Transmission of Bartonella henselae by Ixodes ricinus. Emerg Infect Dis. 2008;14 (7):1074-1080. doi:10.3201/eid1407.071110

69. Adelson M, Rao R, Tilton R, et al. Prevalence of Borrelia burgdorferi, Bartonella spp; Babesia microti, and Anaplasma phagocytophila in ixodes scapularis ticks collected in Northern New Jersey. J Clin Microbiol. 2004;42:2799-2801. doi:10.1128/ JCM.42.6.2799-2801.2004

70. Holden K, Boothby J, Kasten R, Chomel B. Co-detection of Bartonella henselae, Borrelia burgdorferi, and Anaplasma phagocytophilum in Ixodes pacificus Ticks from California, USA. Vector Borne Zoonotic Dis. 2006;6:99-102. doi:10.1089/vbz.2006.6.99

71. Halos L, Jamal T, Maillard R, et al. Evidence of Bartonella sp. in questing adult and nymphal Ixodes ricinus ticks from France and co-infection with Borrelia burgdorferi sensuo lato and Babesia spp. Vet Res. 2005;36:79-87. doi:10.1051/vetres:2004052

72. Eskow E, Rao R, Mordechai E. Concurrent infection of the central nervous system by Borrelia burgdorferi and Bartonella henselae. Arch Neurol. 2001;58:1357. doi:10.1001/archneur.58.9.1357

73. Podsiadly E, Chmielewski T, Tylewska-Wierzbanowska S. Bartonella henselae and Borrelia burgdorferi infections of the central nervous system. Ann NY Acad Sci. 2003;990:404-406. doi:10.1111/j.1749-6632.2003.tb07400.x

74. Canneti B, Cabo-López I, Puy-Núñez A, et al. Neurological presentations of Bartonella henselae infection. Neurol Sci. 2019;40:261-268. doi:10.1007/s10072-018-3618-5
75. Breitschwerdt EB, Sontakke S, Hopkins S. Neurological manifestations of Bartonellosis in immunocompetent patients: a composite of reports from 2005-2012. J Neuroparasitology. 2012;3:1-15. doi:10.4303/jnp/235640

76. Flegr J, Preiss M, Balátová P. Depressiveness and neuroticism in bartonella seropositive and seronegative subjects-Preregistered Case-Controls Study. Front Psychiatry. 2018;9:314. doi:10.3389/ fpsyt.2018.00314

77. Breitschwerdt EB, Greenberg R, Maggi RG, Mozayeni BR, Lewis A, Bradley JM. Bartonella henselae bloodstream infection in a boy with pediatric acute-onset neuropsychiatric syndrome. J Cent Nerv Syst Dis. 2019;11:1179573519832014. doi:10.1177/1179573519832014

78. Chiuri RM, Matronola MF, Giulio CD, Comegna L, Chiarelli F, Blasetti A. Bartonella henselae infection associated with autoimmune thyroiditis in a Child. Horm Res Paediatr. 2013;79 (3):185-188. doi:10.1159/000346903

79. Van Audenhove A, Verhoef G, Peetermans WE, Boogaerts M, Vandenberghe P. Autoimmune haemolytic anaemia triggered by Bartonella henselae infection: a case report. $\mathrm{Br} J$ Haematol. 2001;115(4):924-925. doi:10.1046/j.1365-2141.2001.03165.X

80. Tsukahara M, Tsuneoka H, Tateishi H, Fujita K, Uchida M. Bartonella infection associated with systemic juvenile rheumatoid arthritis. Clin Infect Dis. 2001;32(1):E22-E23. doi:10.1086/317532

81. Cozzani E, Cinotti E, Ameri P, Sofia A, Murialdo G, Parodi A. Onset of cutaneous vasculitis and exacerbation of IgA nephropathy after Bartonella henselae infection. Clin Exp Dermatol. 2011;37(3):238-240. doi:10.1111/j.1365-2230.2011.04177.x

82. Hopp L, Eppes SC. Development of IgA nephritis following cat scratch disease in a 13-year-old boy. Pediatr Nephrol. 2004;19 (6):682-684. doi:10.1007/s00467-004-1432-1

83. Giladi M, Maman E, Paran D, et al. Cat-scratch disease-associated arthropathy. Arthritis Rheum. 2005;52 (11):3611-3617. doi:10.1002/art.21411

84. Maggi RG, Mozayeni BR, Pultorak EL, et al. Bartonella spp. Bacteremia and rheumatic symptoms in patients from lyme disease-endemic region. Emerg Infect Dis. 2012;18(11):1919-1921. doi:10.3201/eid1811.121226

85. Durey A, Kwon HY, Im J-H, et al. Bartonella henselae infection presenting with a picture of adult-onset stills disease. Int $J$ Infect Dis. 2016;46:61-63. doi:10.1016/j.ijid.2016.03.014

86. Stockmeyer B, Schoerner C, Frangou P, Moriabadi T, Heuss D, Harrer T. Chronic vasculitis and polyneuropathy due to infection with Bartonella henselae. Infection. 2007;35(2):107-109. doi:10.1007/s15010-007-6021-3

87. Massei F, Gori L, Taddeucci G, Macchia P, Maggiore G. Bartonella henselae infection associated with guillain-barré syndrome. Pediatr Infect Dis J. 2006;25:90-91. doi:10.1097/01. inf.0000195642.28901.98

88. Balakrishnan N, Ericson M, Maggi R, Breitschwerdt EB. Vasculitis, cerebral infarction and persistent Bartonella henselae infection in a child. Parasit Vectors. 2016;9(1):254. doi:10.1186/ s13071-016-1547-9

89. Palumbo E, Sodini F, Boscarelli G, Nasca G, Branchi M, Pellegrini G. Immune thrombocytopenic purpura as a complication of Bartonella henselae infection. Infez Med. 2008;16(2):99-102.

90. Ayoub EM, Mcbride J, Schmiederer M, Anderson B. Role of Bartonella henselae in the etiology of Henoch-Schönlein purpura. Pediatr Infect Dis J. 2002;21(1):28-31. doi:10.1097/00006454200201000-00006

91. Robinson JL, Spady DW, Prasad E, McColl D, Artsob H. Bartonella seropositivity in children with Henoch- Schönlein purpura. BMC Infect Dis. 2005;5:21. doi:10.1186/1471-2334-5-21

92. Kinderlehrer DA. Is bartonella a cause of primary sclerosing cholangitis? A Case Study. Gastrointest Disord. 2020;2 (1):48-57. doi:10.3390/gidisord2010005 
93. Craft JE, Fischer DK, Shimamoto GT, Steere AC. Antigens of Borrelia burgdorferi recognized during lyme disease. Appearance of a new immunoglobulin $\mathrm{M}$ response and expansion of the immunoglobulin $\mathrm{G}$ response late in the illness. J Clin Invest. 1986;78(4):934-939. doi:10.1172/JCI112683

94. Steere AC, Hardin JA, Ruddy S, Mummaw JG, Malawista SE. Lyme arthritis: correlation of serum and cryoglobulin IgM with activity, and serum IgG with remission. Arthritis Rheum. 1979;22 (5):471-483. doi:10.1002/art.1780220506

95. Fried MD, Adelson ME, Mordechai E. Simultaneous gastrointestinal infections in children and adolescents. Pract Gastroenterol. 2004;28:78-80.

96. Breitschwerdt EB, Bradley JM, Maggi RG, Lashnits E, Reicherter P. Bartonella Associated Cutaneous Lesions (BACL) in people with neuropsychiatric symptoms. Pathogens. 2020;9: 1023. doi:10.3390/pathogens9121023

97. Maluki A, Breitschwerdt E, Bemis L, et al. Imaging analysis of Bartonella species in the skin using single-photon and multiphoton (second harmonic generation) laser scanning microscopy. Clin Case Rep. 2020;8(8):1654. doi:10.1002/ccr3.2939

98. Rolain JM, Brouqui P, Koehler JE, Maguina C, Dolan MJ, Raoult D. Recommendations for treatment of human infections caused by Bartonella species. Antimicrob Agents Chemother. 2004;48(6):1921-1933. doi:10.1128/AAC.48.6.1921-1933.2004

99. Drummond MR, Gilioli R, Velho PE. Bartonellosis diagnosis requires careful evaluation. Braz J Infect Dis. 2010;14(3):217. doi:10.1016/S1413-8670(10)70045-3

100. Okaro U, Addisu A, Casanas B, Anderson B. Bartonella species, an emerging cause of blood-culture-negative endocarditis. Clin Microbiol Rev. 2017;30(3):709-746.

101. de Barbeyrac B, Obeniche F, Ratsima E, et al. Limites et perspectives du diagnostic sérologique à l'ère de l'amplification génique in vitro: infections génitales à Chlamydia trachomatis et infections respiratoires à Chlamydia pneumoniae et Mycoplasma pneumoniae [Serologic diagnosis of chlamydial and Mycoplasma pneumoniae infections]. Ann Biol Clin. 2006;64(5):409-419. Article in French.
102. Roham M, Anbari K, Mirhabibi S, Goudarzi G. The seroprevalence of Mycoplasma pneumoniae IgM and IgG antibodies in patients with ischemic stroke. Iran J Microbiol. 2016;8(6):3 83-388.

103. Woods CR. False-positive results for immunoglobulin M serologic results: explanations and examples. J Pediatr Infect Dis Society. 2013;2(1):87-90. doi:10.1093/jpids/pis133

104. Vannier E, Gewurz BE, Krause PJ. Human babesiosis. Infect Dis Clin North Am. 2008;22(3):469. doi:10.1016/j.idc.2008.03.010

105. Ramesh G, Didier PJ, England JD, et al. Inflammation in the pathogenesis of lyme neuroborreliosis. Am J Pathol. 2015;185 (5):1344-1360. doi:10.1016/j.ajpath.2015.01.024

106. Fallon BA, Levin ES, Schweitzer PJ, Hardesty D. Inflammation and central nervous system lyme disease. Neurobiol Dis. 2010;37 (3):534-541. doi:10.1016/j.nbd.2009.11.016

107. Singh SK, Girschick HJ. Lyme borreliosis: from infection to autoimmunity. Clin Microbiol Infect. 2004;10(7):598-614. doi:10.1111/j.1469-0691.2004.00895.x

108. Chandra A, Wormser GP, Klempner MS, et al. Anti-neural antibody reactivity in patients with a history of lyme borreliosis and persistent symptoms. Brain Behav Immun. 2010;24(6):10 18-1024. doi:10.1016/j.bbi.2010.03.002

109. Rhee H, Cameron DJ. Lyme disease and pediatric autoimmune neuropsychiatric disorders associated with streptococcal infections (PANDAS): an overview. Int J Gen Med. 2012;5:163-174. doi:10.2147/IJGM.S24212

110. Lochner C, Seedat S, Du Toit PL, et al. Obsessive-compulsive disorder and trichotillomania: a phenomenological comparison. BMC Psychiatry. 2005;5:2. doi:10.1186/1471-244X-5-2

\section{Publish your work in this journal}

The International Medical Case Reports Journal is an international, peer-reviewed open-access journal publishing original case reports from all medical specialties. Previously unpublished medical posters are also accepted relating to any area of clinical or preclinical science. Submissions should not normally exceed 2,000 words or 4 published pages including figures, diagrams and references. The manuscript management system is completely online and includes a very quick and fair peer-review system, which is all easy to use. Visit http://www.dovepress.com/testimonials.php to read real quotes from published authors 